\title{
Changes in propagule formation and plant growth in Potamogeton crispus induced by exogenous application of gibberellic acid $\left(\mathrm{GA}_{3}\right)$ and 6-benzyladenine (6-BA)
}

\author{
Lei Wang ${ }^{1}$, Tewu Yang ${ }^{1, *}$, Duanwei $\mathrm{Zhu}^{2}{ }^{2}$ Junchi Xu ${ }^{1}$, Zhongnan $\mathrm{Nie}^{3}$, Guozheng Yang ${ }^{1}$ \\ ${ }^{1}$ College of Plant Science and Technology, Huazhong Agricultural University, Wuhan 430070, PR China \\ ${ }^{2}$ Laboratory of Plant Nutrition and Ecological Environment Research, Center for Microelement Research, \\ Huazhong Agricultural University, and Key Laboratory of Subtropical Agriculture and Environment, \\ Ministry of Agriculture, Wuhan 430070, PR China \\ ${ }^{3}$ Department of Primary Industries, Private Bag 105, Hamilton, Victoria 3300, Australia
}

\begin{abstract}
Submerged aquatic macrophytes such as Potamogeton crispus can absorb large quantities of nutrients from sediment and water, and therefore mitigate pollution and improve water quality of polluted lakes. Turions are the main propagules of $P$. crispus; their formation is an important process in the life cycle of the plant and relates closely to the population dynamics of the species in lakes. The clarification of the physiological mechanisms specific to plant hormone regulation in propagule formation versus plant growth will help to better understand the population decline in eutrophic waters and to develop management strategies for the species. In the present study, different treatment concentrations and application frequencies of gibberellic acid $\left(\mathrm{GA}_{3}\right)$ and 6-benzyladenine (6-BA), a cytokinin substances, were used to investigate their effects on propagule formation and plant growth in this plant. The results showed that, when a cultured plant was treated with $\mathrm{GA}_{3}$ or 6-BA before propagule morphogenesis, propagule production was inhibited or delayed. Under repeat applications of $\mathrm{GA}_{3}$ or 6-BA, propagule formation was arrested completely except in the treatment with $2.5 \mathrm{mg} \mathrm{l}^{-1} \mathrm{GA}_{3}$, which led to some phylloclade turions. Plants treated with $\mathrm{GA}_{3}$ had more phylloclade turions and longer turions compared to the control, whereas less difference was observed under 6-BA treatments. This suggests that cytokinin is a more effective substance in regulating propagule differentiation in P. crispus. Morphological and physiological analysis showed that the propagule formation was more sensitive than plant growth to the plant growth regulators. Both plant growth regulators promoted photosynthetic pigments in plants but inhibited starch accumulation in propagules, which may be related closely to the changes in propagule growth and development.
\end{abstract}

KEY WORDS: Turion · Cytokinin · Gibberellin · Carbohydrate accumulation · Physiological characteristics

\section{INTRODUCTION}

Degradation in shallow lakes and other open wetlands begins with the loss of submerged aquatic vegetation due to turbidity and shading, in which the excessive nutrient loads may lead to high algal bio- mass and loss of biodiversity (Chow-Fraser 1998). Submerged macrophytes can absorb large quantities of pollutants, such as nitrogen, phosphorus and metals from water and sediment (Ali et al. 1999). Friedrich et al. (2003) found that, on average, $>76 \%$ of nitrogen and phosphorus discharged into the 
Danube Delta lakes was taken up by submerged plants and phytoplankton during their growing seasons, and they proposed harvesting submerged and floating biomass to alleviate water pollution. Planting of submerged macrophytes can be an effective way to reduce nutrient content and re-suspension of sediment in water bodies (Hansson et al. 1998) and to repair eutrophication (Hupfer \& Dollan 2003).

Potamogeton crispus is a widespread submerged aquatic plant that grows over winter and generates turions as vegetative propagules in summer in temperate and subtropical zones (Catling \& Dobson 1985). Because of its strong adaptability to polluted water (Tobiessen \& Snow 1984), P. crispus has been widely used as a pioneer species in re-vegetating degraded lakes in China (Wu et al. 2009). Although the plant can occasionally produce seeds (Chen et al. 2006), seed germination is extremely low $(0.001 \%)$ (Rogers \& Breen 1980). Therefore, turion formation is a major channel for the species to propagate and spread and has a key impact on its population dynamics.

The Potamogeton crispus turion is an abnormal shoot apex with a compressed stem and leaf scales and differentiates from a shoot apical meristem (SAM). Leaf scale, which originates from leaf but has a smaller area and harder texture, is highly enriched with a nonstructural carbohydrate reserve (mainly starch) (Sastroutomo et al. 1979). There are 2 morphological types of turions in P. crispus: standard turion and phylloclade turion. The standard turion usually grows from the apex of a stem or a branch, and is considerably larger than the phylloclade turion, which usually grows from leaf axils. A larger propagule is hypothesized to support the higher competitive ability of young seedling(s) because of a larger starch reserve during propagule germination in aquatic plants (Grace 1985, Spencer \& Rejmanek 1989).

The carbohydrate reserve in turions is derived from photosynthetic assimilation in the plant. Therefore, plant physiological characteristics such as photosynthetic strength, chlorophyll content, and carbon and nitrogen metabolisms, particularly at the stem apices where turions form, may have impacts on the reserve accumulation in turions. Spencer \& Anderson (1987) observed degradations in chlorophyll a ( $\mathrm{chl}$ a) and carotenoids in leaves when propagule formation was induced and plant senescence initiated under short photoperiods in Potamogeton nodosus. Woolf \& Madsen (2003) found that thick and robust plants that contain high levels of total nonstructural carbohydrates tend to produce larger turions in $P$. crispus in lakes. Huang et al. (2010) reported that an increase in turion weight coincided with increases in leaf pho- tosynthetic efficiency and total biomass in P. crispus under higher nitrogen and phosphorus availability in sediment within a certain range. James (2007) found that plant growth, turion development, and carbohydrate accumulation in turions were simultaneously suppressed by the application of lime to P. crispus, due to lower photosynthesis in leaves resulting from the lime-induced dissolved inorganic carbon limitation in the water.

Many aquatic plants produce vegetative propagules such as turions and tubers in order to survive unfavorable conditions and to ensure vegetative reproduction (Sculthorpe 1967). Under natural conditions, turions of Potamogeton crispus start to form when light, temperature, and day length increase in summer (Kunii 1989). Chambers et al. (1985) showed that turion formation was triggered by long photoperiods $\left(\geq 16 \mathrm{~h} \mathrm{~d}^{-1}\right)$ and a certain level of light intensity, when the ratio of red light to far-red light was $>1$. Sastroutomo (1980) found a combined effect of temperature and photoperiod in regulating turion formation in P. crispus. Turion initiation was induced under a daily mean air temperature range of $13-24^{\circ} \mathrm{C}$ on both 12 and $16 \mathrm{~h}$ days, and $24-35^{\circ} \mathrm{C}$ on $8 \mathrm{~h}$ days.

Propagule production has been found to be influenced by plant regulation substances in species other than Potamogeton crispus. Abscisic acid (ABA) has been reported to induce propagule formation in Hydrilla verticillata (Van et al. 1978, Klaine \& Ward 1984) and Myriophyllum verticillatum (Weber \& Nooden 1976), 2 thermophilic submerged species. Klaine \& Ward (1984) reported that ethylene (applied as ethephon at $2 \mathrm{~d}$ intervals) reduced turion production in $H$. verticillata by $80 \%$. However, there is little information on the function of plant hormones in propagule production in $P$. crispus.

Different nitrogen and phosphorus supplies can induce rapid changes in plant hormone metabolisms and subsequently result in morphological alterations in various organs of a plant (Franco-Zorrilla et al. 2005, Sakakibara et al. 2006). Water eutraphication, mainly due to high nitrogen and phosphorus discharge from poorly managed catchments to freshwater systems such as lakes or reservoirs, has become a big problem in China in the past decades. Furthermore, plant growth regulators such as gibberellinand cytokinin-type substances have been extensively applied in fruit, melon, and other horticultural crops. These regulators may discharge into water bodies when they are used inappropriately. Jana \& Choudhuri (1983) found that kinetin, a cytokinintype substance, could delay leaf senescence and promote plants to take up more phosphorus from water 
and sediment when applied at a concentration of $50 \mathrm{mg} \mathrm{l}^{-1}$ in Potamogeton pectinatus, Vallisneria spiralis, and Hydrilla verticillata. Sastroutomo (1981) reported that gibberellic acid $\left(\mathrm{GA}_{3}\right)$ could fully break turion dormancy and promote shoot elongation in light when applied both at 21.5 and $215 \mathrm{mg} \mathrm{l}^{-1}$ in $P$. crispus. However, very little is known about the roles of these substances, if any, on propagule formation of aquatic plants.

In the present study, we compared the effects of $\mathrm{GA}_{3}$, a gibberellin, and 6-benzyladenine (6-BA), a cytokinin, on turion formation and plant growth in Potamogeton crispus. The objectives were to understand the regulation of plant hormones on plant growth and development and to develop management strategies for the species, which plays a significant role in pollution control in lakes.

\section{MATERIALS AND METHODS}

\section{Sampling and incubation}

A local ecotype of Potamogeton crispus was collected from a pond near Lake Nanhu $\left(30^{\circ} 28^{\prime} 20^{\prime \prime} \mathrm{N}\right.$, $114^{\circ} 21^{\prime} 49^{\prime \prime}$ E) in Wuhan, Central China on 22 March 2008. Plant materials were kept in buckets filled with water, and immediately transported to a controlled culture experimental field with a movable transparent rain-proof shelter installed about $2.5 \mathrm{~m}$ above ground. After the materials were gently cleaned from epiphytes with tap water, apical stems of about $7 \mathrm{~cm}$ in length without root were cut from individual plants, and 10 apical stems were then transplanted into each bucket $(16 \mathrm{~cm}$ in diameter and $22 \mathrm{~cm}$ in depth), using acid-rinsed quartz sand as matrix. The incubators were filled with $10 \%$ nitrogen- and phosphorus-free Hoagland solution, and the nitrogen concentration was subsequently adjusted to $0.25 \mathrm{mg} \mathrm{l}^{-1}$ with $\mathrm{NH}_{4} \mathrm{NO}_{3}$, and phosphorus concentration to $0.025 \mathrm{mg} \mathrm{l}^{-1}$ with $\mathrm{NaH}_{2} \mathrm{PO}_{4}$. The materials were cultured for $6 \mathrm{~d}$ before the treatments were conducted.

\section{Treatment}

A multi-factorial (2 regulators $\times 2$ concentrations $\times$ 2 applications) design with 3 replicates was used. Cultured plants were treated with a solution containing a low $\left(2.5 \mathrm{mg} \mathrm{l}^{-1}\right)$ or high $\left(25 \mathrm{mg} \mathrm{l}^{-1}\right)$ concentration of $\mathrm{GA}_{3}$ or 6 -BA on 28 March 2008. The 2 application methods were either a single treatment for $4 \mathrm{~h}$ on the first day only, or repeat treatments every $3 \mathrm{~d}$ for $4 \mathrm{~h}$ each time (10 times in total until trial termination on 30 April 2008). The treatment combinations were: (1) $\mathrm{GA}_{3}$ + low concentration + single application (GALS); (2) $\mathrm{GA}_{3}+$ high concentration + single application (GAHS); (3) $\mathrm{GA}_{3}+$ low concentration + repeat applications (GALR); (4) $\mathrm{GA}_{3}+$ high concentration + repeat applications (GAHR); (5) 6-BA + low concentration + single application (BALS); (6) 6-BA + high concentration + single application (BAHS); (7) 6-BA + low concentration + repeat applications (BALR); and (8) 6-BA + high concentration + repeat applications (BAHR). After the regulator treatments, plants were rinsed immediately and then cultured in regulatorfree incubation solution. In addition, plants growing in regulator-free solution were used as a control. Incubation solutions were replaced every $3 \mathrm{~d}$ for maintaining the nutrient concentrations and suppressing algal growth throughout the experiment. For repeat applications, the treatments were re-applied prior to the incubation-solution change each time.

The 27 buckets in total were arranged randomly in a completely randomized design. A rain-proof shelter was used to cover the buckets and prevent contamination and dilution of the solutions when rainfall occurred. During the course of the experiment, day length ranged from 12.29 to $13.52 \mathrm{~h} \mathrm{~d}^{-1}$, midday photosynthetically active radiation ranged from 200 to $1000 \mu \mathrm{mol} \mathrm{m} \mathrm{m}^{-2} \mathrm{~s}^{-1}$, and average daily mean air temperature was $17.1^{\circ} \mathrm{C}$ (ranging from 14.1 to $21.5^{\circ} \mathrm{C}$ ).

\section{Morphology}

Turion formation on individual plants was closely observed daily during the trials. On 30 April 2008, when turions of the control plants were close to maturity (their color began to turn brown from green and the structure became hardened; Huang et al. 2010), plants of all treatments were harvested and initially rinsed with tap water, then cleaned with distilled water. Propagule production and plant growth were then measured, including the number of propagules, number of leaf scales, length and fresh weight of standard and phylloclade turions, plant height, number of nodes on the caulis (stem), length of branches (both primary and secondary branches), and fresh biomass of individual plants. Fresh samples were oven-dried at $105^{\circ} \mathrm{C}$ for $30 \mathrm{~min}$ initially and maintained at $80^{\circ} \mathrm{C}$ until constant dry weights were achieved to determine the dry biomass of the turions and plants (Yang et al. 2010). 


\section{Physiology}

Chl $a$, chlorophyll $b$ (chl $b$ ), and carotenoid (car) contents were analyzed in harvested fresh plants. The photosynthetic pigment was extracted from $0.2 \mathrm{~g}$ fresh sample from the top 6 nodes of stems in a test tube with $5 \mathrm{ml}$ of $95 \%$ ethanol at $70^{\circ} \mathrm{C}$ in dark until it was totally discolored. Light absorbance of the extract was measured at 470,649, and $665 \mathrm{~nm}$. The contents (in $\mathrm{mg} \mathrm{g}^{-1}$ fresh weight [FW]) of $\mathrm{chl} a$, chl $b$, and car were calculated by the following formulae (Hu et al. 2007):

$$
\begin{aligned}
\text { chl } a= & \left(13.95 A_{665}-6.88 A_{649}\right) \times 10^{-3} \times V_{\mathrm{t}} \times N / \mathrm{FW} \\
\text { chl } b= & \left(24.96 A_{649}-7.32 A_{665}\right) \times 10^{-3} \times V_{\mathrm{t}} \times N / \mathrm{FW} \\
\text { car }= & \left(4.08 A_{470}-3.31 A_{665}-11.64 A_{649}\right) \\
& \times 10^{-3} \times V_{\mathrm{t}} \times N / \mathrm{FW}
\end{aligned}
$$

where $V_{\mathrm{t}}$ and $N$ represent total volume $(\mathrm{ml})$ and dilution times of the extract, respectively, and $A$ is the absorbance at a specific wavelength $(470,649$, or $665 \mathrm{~nm}$ ).

Soluble protein was extracted from $0.2 \mathrm{~g}$ dried powder of harvested plants in $25 \mathrm{ml}$ distilled water, and followed by centrifugation at $1400 \times g$ for $10 \mathrm{~min}$. One $\mathrm{ml}$ of supernatant and $5 \mathrm{ml}$ Folin-phenol A solution were added to a test tube and blended, and placed in $30^{\circ} \mathrm{C}$ for $10 \mathrm{~min}$. Then $0.5 \mathrm{ml}$ of Folin-phenol B solution was added and mixed immediately. This was kept at $30^{\circ} \mathrm{C}$ for $30 \mathrm{~min}$, and then the soluble protein content was determined by colorimetric assay at $650 \mathrm{~nm}$, using bovine serum albumin (BSA) as a standard (Lowry et al. 1951).

Soluble sugar, sucrose and starch contents were analyzed in harvested plants and turions using the anthrone method (Dreywood 1946, Yemm \& Willis 1954). Dried powder $(0.2 \mathrm{~g})$ of samples was homogenized in $80 \%$ ethanol and then centrifuged at $800 \times g$ for 10 min following incubation in an $80^{\circ} \mathrm{C}$ water bath for $30 \mathrm{~min}$. The same extraction procedure was repeated 3 times and the supernatant amalgamated to make up to $100 \mathrm{ml}$. A volume of $0.2 \mathrm{ml}$ supernatant and $1.8 \mathrm{ml}$ distilled water were put into a test tube to determine soluble sugar. After reacting with $0.5 \mathrm{ml}$ anthrone reagent and $5 \mathrm{ml}$ sulfuric acid in boiling water for $1 \mathrm{~min}$, light absorbance was measured at $630 \mathrm{~nm}$. For sucrose analysis, $0.5 \mathrm{ml}$ supernatant was put into a test tube together with $0.2 \mathrm{ml} 30 \% \mathrm{KOH}$ and $1.5 \mathrm{ml}$ distilled water. After placement in boiling water for $10 \mathrm{~min}$ and then adding $0.5 \mathrm{ml}$ anthrone reagent and $5 \mathrm{ml}$ sulfuric acid, the same reaction procedure and colorimetric assay were conducted to measure soluble sugar. The reducing sugar content was calculated by subtracting the sum of sucrose from soluble sugar.
After sugar extraction, the supernatant was decanted and the sediment dried at $80^{\circ} \mathrm{C}$ for determining starch. Twenty $\mathrm{ml}$ of $1.12 \% \mathrm{HCl}$ was added to hydrolyze the starch thoroughly, in a boiling water bath. The soluble sugar content was determined in the hydrolysate and starch content was calculated from the soluble sugar content (Dreywood 1946, Yemm \& Willis 1954).

\section{Statistical analyses}

Data on propagule production and plant growth metrics of all treatments were analyzed using 3-way ANOVA, with plant growth regulator, treatment concentration, and frequency as the main factors. Prior to running the ANOVA, the data with non-normal distributions were transformed as $x^{\prime}=\sqrt{x+1}$ for the turion number and biomass, and the numbers of primary and secondary branches. Duncan's multiple comparison was used to test the significance of differences at $\alpha=0.05$. For the morphological and physiological metrics of propagules, differences were compared only between the treatments that produced propagules and the control. All data analyses were performed using SPSS 11.5.0.

\section{RESULTS}

\section{Propagule production}

Observations showed that turion formation in Potamogeton crispus was inhibited or delayed under $\mathrm{GA}_{3}$ and 6-BA treatments compared to the control. Plants in the control began to produce turions on Day 13 of the experiment, $12 \mathrm{~d}$ earlier than those in the treatments GALS and BALS. Measurement at harvest indicated significant differences in turion production between treatments and control (Table 1). Turion formation was arrested completely in BALR, BAHR and GAHR. The average number of standard turions per plant was significantly $(p<0.05)$ lower for GALS and BAHS, and the average number of phylloclade turions per plant for GALS and the dry biomass of individual phylloclade turions for GALR were significantly $(p<0.05)$ higher than those for the control. But no significant differences $(p>0.05)$ were found between the remaining treatments that produced propagules and the control, in the average number of both types of turions per plant and/or dry biomass of individual turions (Table 1). The total number of propagules (standard and phylloclade turions) per 
Table 1. Potamogeton crispus. Propagule growth under treatment with gibberellic acid (GA 3 ) or 6-benzyladenine (6-BA). Data are mean \pm SE. Different superscripted letters indicate significant differences $(p<0.05)$ within a column. GALS: GA $3+$ low concentration + single application; GALR: $\mathrm{GA}_{3}+$ low concentration + repeat applications; GAHS: $\mathrm{GA}_{3}+$ high concentration + single application; GAHR: GA 3 + high concentration + repeat applications; BALS: 6-BA + low concentration + single application; BALR: 6-BA + low concentration + repeat applications; BAHS: 6-BA + high concentration + single application; BAHR: 6-BA + high concentration + repeat applications. na: not applicable

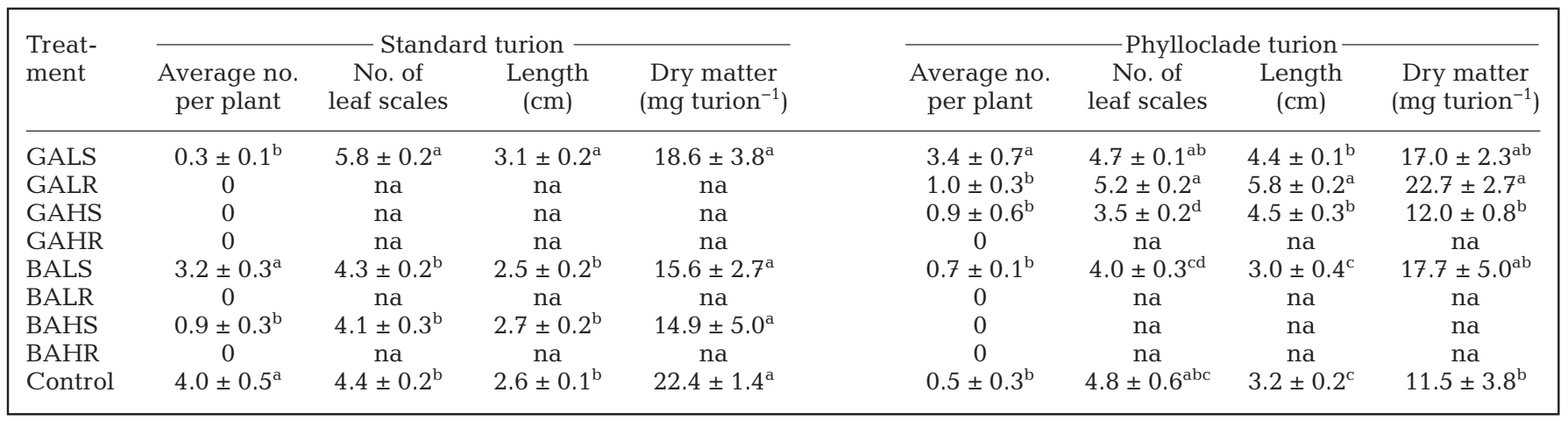

plant was significantly $(\mathrm{p}<0.05)$ lower in the regulator treatments than in the control except in treatments GALS and BALS.

Most of the turions that formed in the control treatment were standard turions and only $11.1 \%$ were phylloclade turions. In the $\mathrm{GA}_{3}$ treatments that produced turions, however, $>90 \%$ were phylloclade turions (Table 1). In the 6-BA treatment which produced both types of turions (BALS), there was no significant difference $(p>0.05)$ in the ratio of the 2 types of turions in comparison with the control.

Compared to the control, the lengths of both types of turions were significantly $(p<0.05)$ greater for $\mathrm{GA}_{3}$ treatments; the number of leaf scales of standard turions was higher for GALS, but that of phylloclade turions was lower for GAHS (Table1). No significant difference was detected in the length or number of leaf scales of propagules between the 6-BA treatments and the control.

Dry biomass of standard turions and total propagules per plant was significantly $(p<0.05)$ lower for the regulator treatments that produced propagules than the control (Fig. 1A,C). However, dry biomass of phylloclade turions per plant was higher $(p<0.05)$ in GALS than in the control (Fig. 1B).

\section{Plant growth}

There was an overall trend of increase in plant height, the number and length of primary branches, and dry biomass of stems and leaves under $\mathrm{GA}_{3}$ treatments, compared to the control (Table 2). The differences in all these parameters became significant $(\mathrm{p}<$ 0.05 ) between GALS and the control and between
GAHR and the control. In GALR and GAHS, the length of primary branches and the dry biomass of stems and leaves (GALR only) were significantly ( $\mathrm{p}<$ $0.05)$ greater than the control. There were significant $(p<0.05)$ decreases in the number of nodes on a caulis in GALR and GAHR but not in GALS and GAHS, in comparison with the control (Table 2). The number of nodes on a caulis and dry biomass of stems and leaves in GALS were significantly $(p<0.05)$ higher than those in GAHS. However, there were no significant $(p>0.05)$ differences in the metrics of plant growth between GALR and GAHR (Table 2).

There were greater variations in plant growth among 6-BA treatments. Compared to the control, significant $(p<0.05)$ decreases were observed in plant height, number of nodes on a caulis, and number of primary branches in BALR, BAHS, and BAHR, and in the length of primary branches and the dry biomass of stems and leaves in BAHR. However, there was a significant $(p<0.05)$ increase in the dry biomass of stems and leaves in BALS (Table 2). There was general decrease in the number of nodes on a caulis, the number and length of primary branches, and the dry biomass of stems and leaves with increasing concentration and frequency of application of 6-BA (Table 2). Some secondary branches were found in BAHS only.

\section{Photosynthetic pigment content in plants}

The contents of photosynthetic pigments in plants varied among treatments (Fig. 2). $\mathrm{GA}_{3}$ and 6-BA treatments significantly increased $(p<0.05)$ the total chlorophyll and chl $a$ in plants, except in the BALS 
treatment (Fig. 2A). $\mathrm{GA}_{3}$ promoted chl $b$ content regardless of concentration and frequency of treatment. However, 6-BA promoted chl $b$ only in BALR and BAHS treatments (Fig. 2A). Carotenoid content was significantly $(\mathrm{p}<0.05)$ higher in repeat applications of both regulators, with the exception of GALR compared to the control (Fig. 2B).

\section{Soluble protein content in plants}

Soluble protein content in plants did not change significantly $(p>0.05)$ under both plant growth regulator treatments in comparison with the control, except for a significantly $(\mathrm{p}<0.05)$ lower value detected in GAHR and higher values in BALR and BAHS (Fig. 3). For a single application of the same regulator, high-concentration treatment increased the soluble protein content significantly $(\mathrm{p}<0.05)$, compared to the low concentration. For repeat applications, however, a significant $(p<0.05)$ difference was detected only in the 6-BA treatments, with BAHR plants showing lower soluble protein content than BALR plants (Fig. 3).

\section{Carbohydrate content in plants and propagules}

The contents of soluble sugar and sucrose in plants increased in BALR but decreased to various degrees in other treatments, in comparison with the control (Fig. 4A). The content of reducing sugars was significantly $(\mathrm{p}<0.05)$ higher in the single application of both regulators and BALR than in the control (Fig. 4A). Starch content increased in GALR and GAHS, but
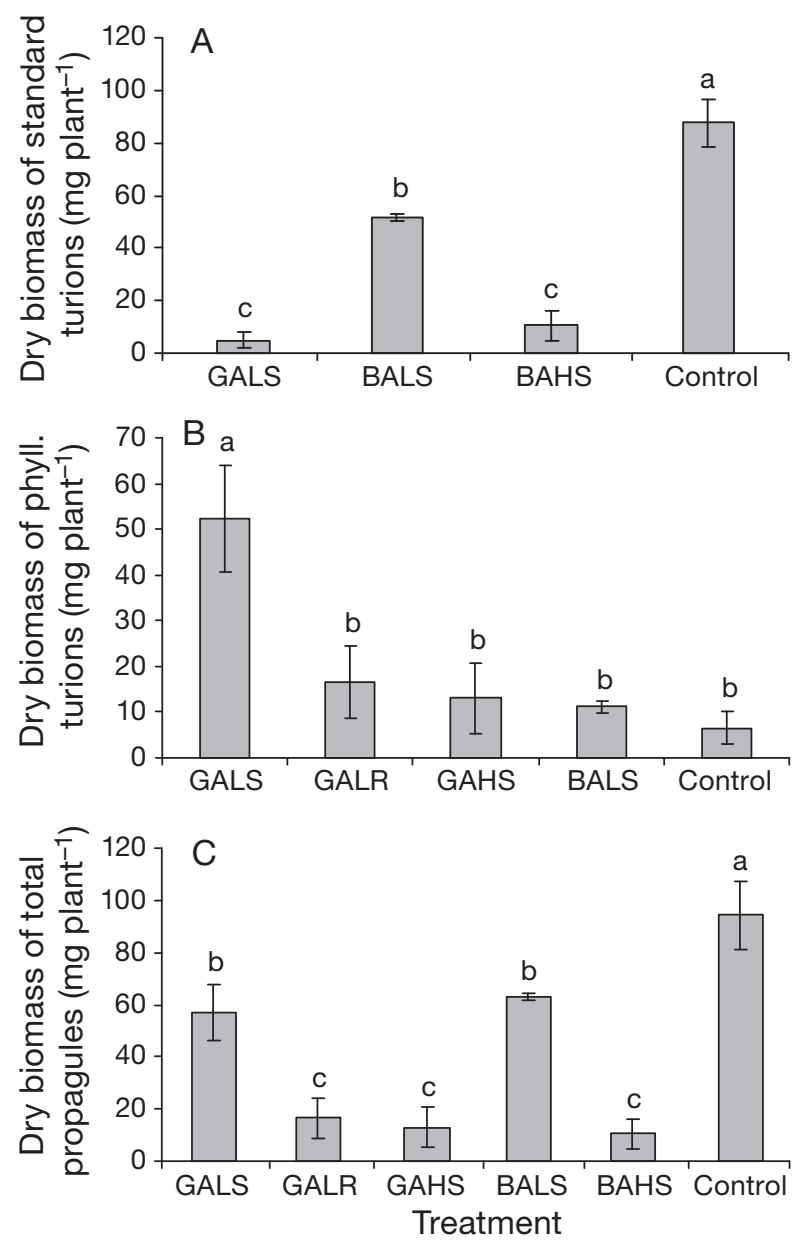

Fig. 1. Potamogeton crispus. Dry biomass per plant of (A) standard turions, (B) phylloclade turions, and (C) total propagules under treatment with gibberellic acid $\left(\mathrm{GA}_{3}\right)$ or 6 benzyladenine (6-BA). Different letters above SE bars indicate significant differences $(p<0.05)$ between treatment groups. See Table 1 caption for treatment abbreviations

Table 2. Potamogeton crispus. Morphological characteristics of plants under treatment with gibberellic acid (GA $)_{3}$ or 6 -benzyladenine (6-BA). Data are mean \pm SE. Different superscripted letters indicate significant differences $(p<0.05)$ within a column. na: not applicable. See Table 1 caption for treatment abbreviations

\begin{tabular}{|c|c|c|c|c|c|c|c|}
\hline $\begin{array}{l}\text { Treat- } \\
\text { ment }\end{array}$ & $\begin{array}{l}\text { Plant height } \\
\text { (cm) }\end{array}$ & $\begin{array}{l}\text { No. of nodes } \\
\text { on caulis }\end{array}$ & $\begin{array}{l}\text { Primary } \\
\text { Average no. } \\
\text { per plant }\end{array}$ & $\begin{array}{l}\text { y branches } \\
\text { Average length } \\
\qquad(\mathrm{cm})\end{array}$ & $\begin{array}{l}\text { Seconda } \\
\text { Average no. } \\
\text { per plant }\end{array}$ & $\begin{array}{l}\text { ary branches } \\
\text { Average length } \\
\qquad(\mathrm{cm})\end{array}$ & $\begin{array}{l}\text { Dry matter of stems } \\
\text { and leaves }\left(\mathrm{g} \text { plant }^{-1}\right)\end{array}$ \\
\hline GALR & $36.8 \pm 2.4^{\mathrm{ab}}$ & $20.3 \pm 1.7^{\mathrm{de}}$ & $9.5 \pm 0.9^{\mathrm{ab}}$ & $8.9 \pm 1.7^{\mathrm{ab}}$ & 0 & na & $0.27 \pm 0.02^{\mathrm{ab}}$ \\
\hline GAHS & $36.8 \pm 2.0^{\mathrm{ab}}$ & $24.5 \pm 1.0^{\mathrm{bc}}$ & $8.8 \pm 0.4^{\mathrm{ab}}$ & $6.5 \pm 0.7^{\mathrm{bc}}$ & 0 & na & $0.21 \pm 0.00^{\mathrm{bc}}$ \\
\hline BALR & $21.2 \pm 1.3^{\mathrm{c}}$ & $15.7 \pm 0.3^{\mathrm{f}}$ & $0.9 \pm 0.2^{\mathrm{d}}$ & $3.2 \pm 0.5^{\mathrm{e}}$ & 0 & na & $0.17 \pm 0.01^{\mathrm{de}}$ \\
\hline BAHS & $15.7 \pm 1.0^{\mathrm{d}}$ & $18.3 \pm 1.0^{\mathrm{ef}}$ & $4.2 \pm 1.3^{\mathrm{c}}$ & $4.7 \pm 0.3^{\text {cde }}$ & $1.5 \pm 0.5^{\mathrm{a}}$ & $3.0 \pm 0.2^{\mathrm{a}}$ & $0.17 \pm 0.02^{\mathrm{de}}$ \\
\hline BAHR & $17.5 \pm 0.8^{\mathrm{cd}}$ & $12.8 \pm 0.3^{g}$ & $0.3 \pm 0.3^{\mathrm{d}}$ & $0.8 \pm 0.8^{f}$ & 0 & na & $0.11 \pm 0.01^{\mathrm{e}}$ \\
\hline Control & $33.1 \pm 1.0^{\mathrm{b}}$ & $26.3 \pm 0.7^{\mathrm{ab}}$ & $6.9 \pm 0.6^{\mathrm{b}}$ & $4.2 \pm 0.1^{\mathrm{de}}$ & 0 & na & $0.18 \pm 0.00^{\mathrm{cd}}$ \\
\hline
\end{tabular}



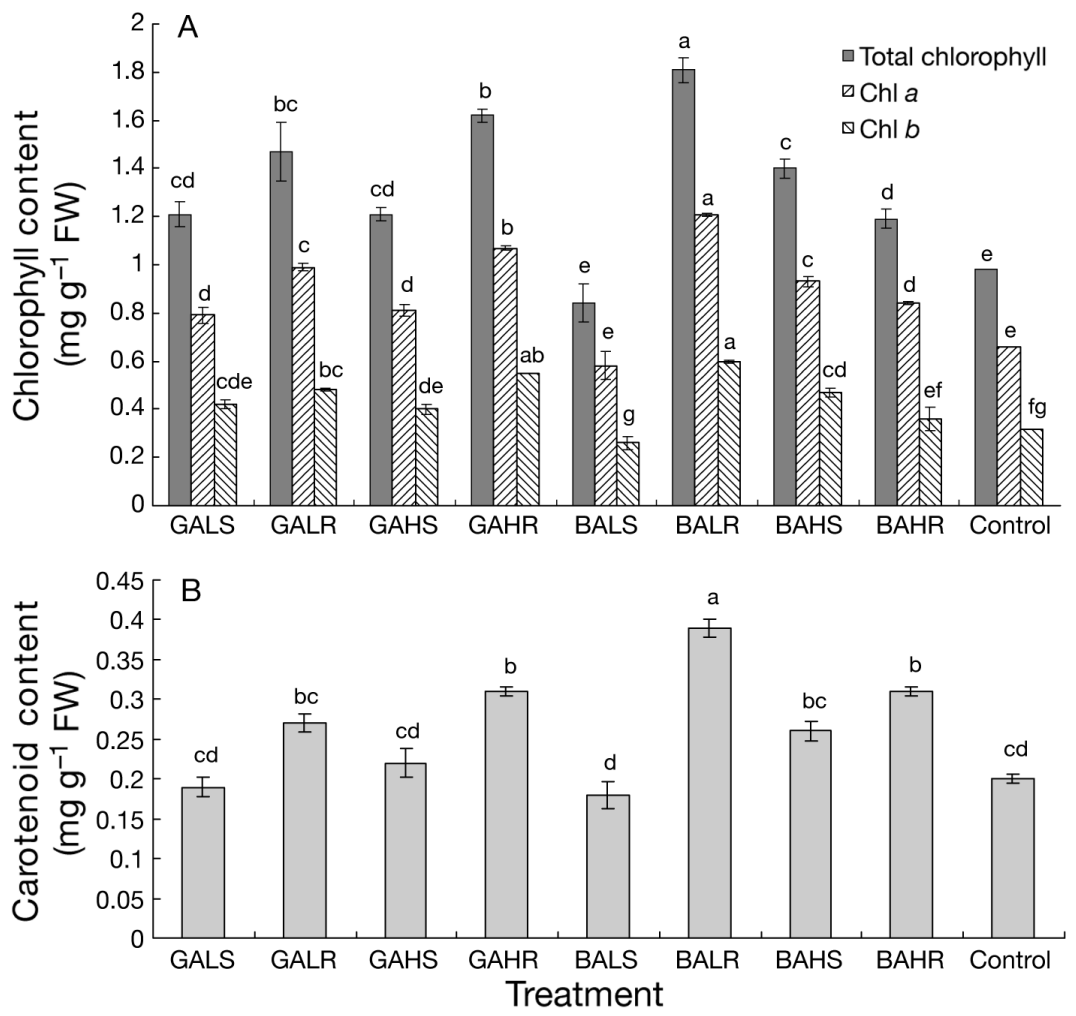

Fig. 2. Potamogeton crispus. Content of (A) total chlorophyll, chl $a$, and chl $b$, and (B) carotenoids in plants under treatment with gibberellic acid $\left(\mathrm{GA}_{3}\right)$ or 6 benzyladenine (6-BA). Different letters above SE bars of the same parameter indicate significant differences $(p<0.05)$ between treatment groups. FW: fresh weight. See Table 1 caption for treatment abbreviations

decreased for 6-BA applications except in BALR in comparison with the control (Fig. 4B). The contents of soluble sugar, sucrose, and starch increased significantly $(\mathrm{p}<0.05)$ with the single-application treatments, but decreased significantly $(p<0.05)$ in repeat applications in the treatments with high concentration of the 2 regulators, compared to the low concentration. This also applied to the content of reducing sugars in repeat applications of 6-BA (Fig. 4).

In propagules, there were significant $(p<0.05)$ increases in the soluble sugar content for all treatments except for GALS, the sucrose content except for GALS and GALR, and the reducing sugar content except for GALS and BAHS (Fig. 5A), compared to control. The starch content in propagules under GAHS and BAHS decreased significantly, compared with the control (Fig. 5B).

Regarding carbohydrate accumulations in propagules per plant, the soluble sugar, sucrose, and reducing sugars decreased in all treatments except for BALS, which had significantly $(\mathrm{p}<0.05)$ higher accumulation of sugars, and GALS, which had a similar level of reducing sugars, compared to the control
(Fig. 6A). Starch accumulation in propagules per plant was significantly $(\mathrm{p}<0.05)$ reduced in all regulator treatments (Fig. 6B). In the singleapplication treatments with the 2 regulators, carbohydrate accumulation in propagules per plant was significantly $(\mathrm{p}<0.05)$ lower at high concentrations compared with low concentrations (Fig. 6).

\section{DISCUSSION}

\section{Regulation of propagule production by plant hormones}

Propagule production is a critical stage in the life cycle of submerged aquatic macrophytes, which depend on vegetative propagules for population dispersal, but the physiological mechanism in the regulation by plant hormones has not yet been clarified. In the present study, we found that propagule formation was inhibited by gibberellin- and cytokinin-type substances in Potamogeton crispus, suggesting the involvement of both substances in the regulation of propagule formation. Klaine (1986) reported that propagule formation was inhibited by the application of thidiazuron $(\mathrm{N}-$ phenyl-N'-1,2,3-thidiazol-5-ylurea), an ethylene stimulator and cotton defoliant with cytokinin-like activity (Mok et al. 1982, Genkov \& Ivanova 1995), in Hydrilla verticillata. Our results revealed that cyto-

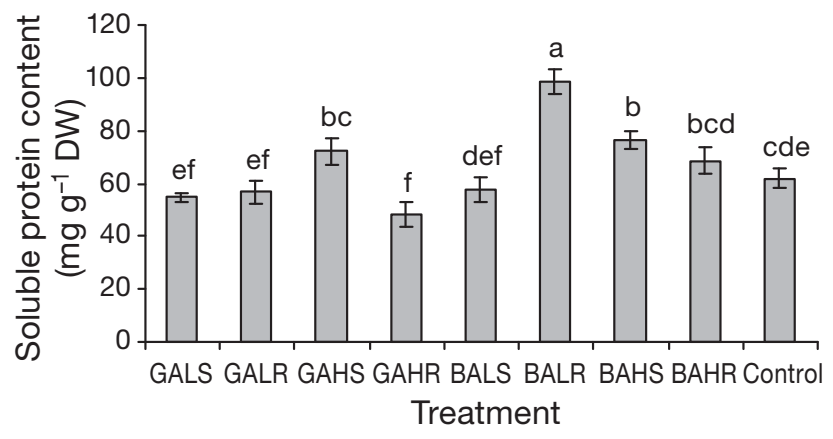

Fig. 3. Potamogeton crispus. Soluble protein content in plants under treatment with gibberellic acid $\left(\mathrm{GA}_{3}\right)$ or 6 benzyladenine (6-BA). Different letters above SE bars indicate significant differences $(p<0.05)$ between treatment groups. DW: dry weight. See Table 1 caption for treatment abbreviations 

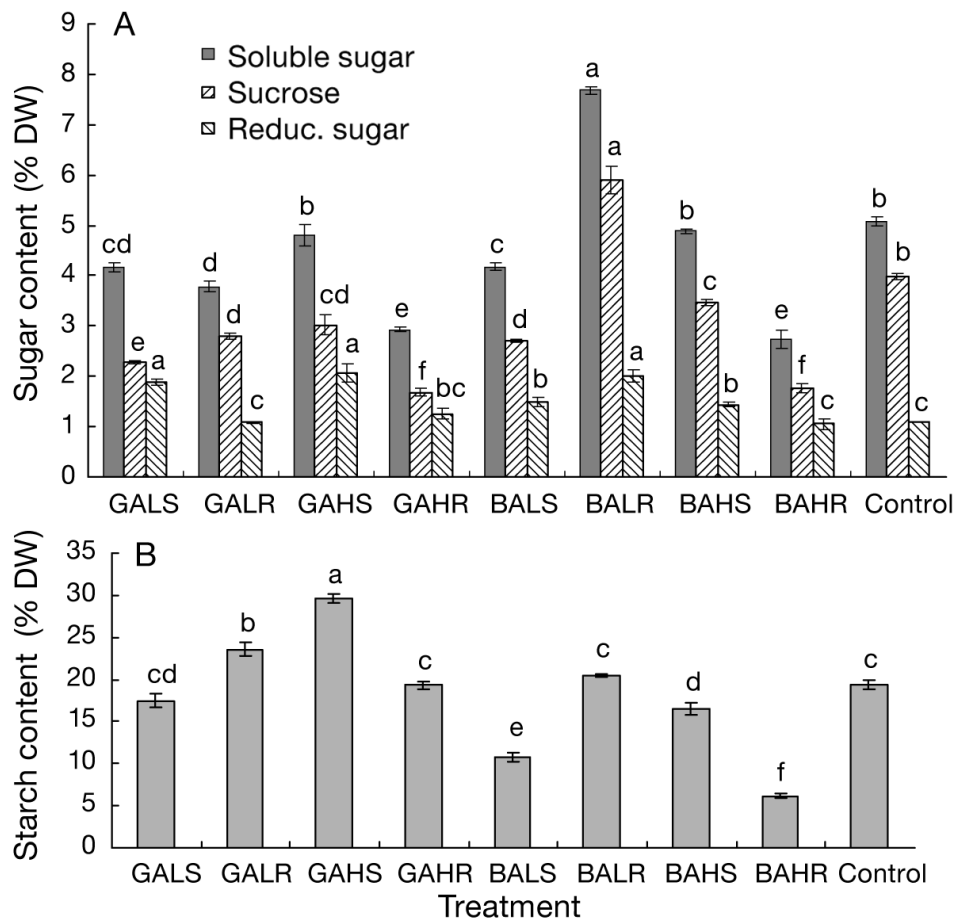

Fig. 4. Potamogeton crispus. Contents of (A) soluble sugar, sucrose, and reducing sugars, and (B) starch in plants under treatment with gibberellic acid $\left(\mathrm{GA}_{3}\right)$ or 6-benzyladenine (6-BA). Different letters above SE bars of the same parameter indicate significant differences $(p<0.05)$ between treatment groups. DW: dry weight. See Table 1 caption for treatment abbreviations

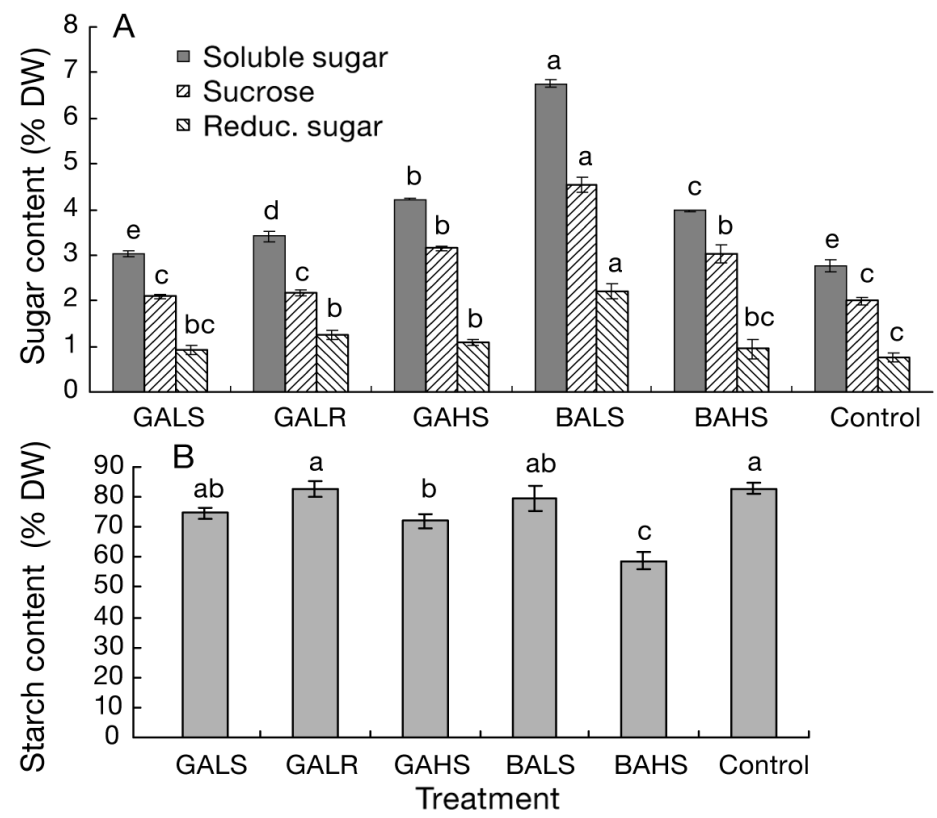

Fig. 5. Potamogeton crispus. Contents of (A) soluble sugar, sucrose, and reducing sugars, and (B) starch in propagules under treatment with gibberellic acid $\left(\mathrm{GA}_{3}\right)$ or 6-benzyladenine (6-BA). Different letters above SE bars of the same parameter indicate significant differences $(p<0.05)$ between treatment groups. DW: dry weight. See Table 1 caption for treatment abbreviations kinin might be more effective than gibberellin in the regulation of propagule formation, because propagule formation was arrested completely by repeat applications of 6 -BA at low concentrations, but not by $\mathrm{GA}_{3}$ in P. crispus.

We also found that there was less morphological variation in propagules under 6-BA treatments than under $\mathrm{GA}_{3}$ treatments compared to the control, probably due to differences in the physiological functions of the 2 regulators. Cytokinin may inhibit differentiation of propagules, but not affect their growth, while gibberellin inhibits both processes and induces some standard turions to develop into smaller phylloclade turions. Because larger turions in Potamogeton crispus show a stronger ability to spread (Shen et al. 2008), a higher rate of phylloclade turion production is unfavorable to this species' propagation in water.

Development and growth of plant organs are largely determined by the activities of SAM. Recent evidence has shown that plant hormones are involved in sensing and signaling extrinsic factors and controlling meristematic activity to mediate the morphological response of a plant in adapting to an environment (Werner \& Schmülling 2009). It is known that nitrate rapidly induces cytokinin and gibberellin biosynthesis in plants (cited in Takei et al. 2001, Ohkama-Ohtsu \& Wasaki 2010), indicating a link between nitrogen nutrition and these hormones. Based on our results that cytokinin and gibberellin altered the differentiation of SAM to propagules in Potamogeton crispus, it is important to establish the links between the metabolisms of endogenous cytokinin and gibberellin and the ambient nutrient status that coincides with decreased propagation in future studies. This would provide a deeper insight into its decline in eutrophic waters, and would be conducive to developing appropriate management methods.

\section{Effects of plant growth regulators on plant growth}

The response of propagule production and plant growth in aquatic plants to plant growth regulators may vary considerably (Smart \& Trewavas 1983). In the present study, propa- 

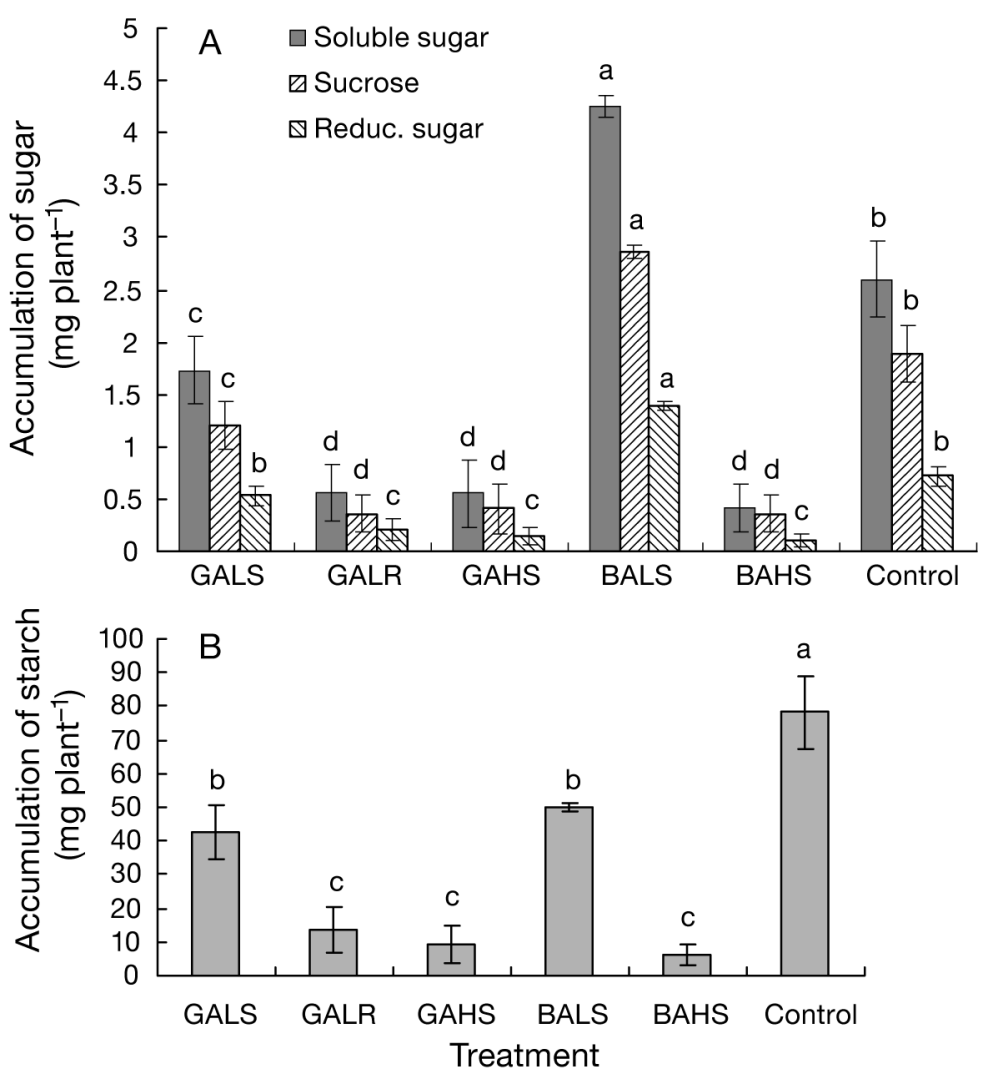

Fig. 6. Potamogeton crispus. Accumulation per plant of (A) soluble sugar, sucrose, and reducing sugars, and (B) starch in propagules under treatment with gibberellic acid $\left(\mathrm{GA}_{3}\right)$ or 6-benzyladenine (6-BA). Different letters above SE bars of the same parameter indicate significant differences $(p<0.05)$ between treatment groups. See Table 1 caption for treatment abbreviations

gule production was inhibited by $\mathrm{GA}_{3}$ and 6 - $\mathrm{BA}$, but plant growth was generally not affected or in some cases it was even promoted, though inhibition was detected in terms of biomass of stems and leaves under the repeat applications of 6 -BA at high concentrations. These results suggest that propagule formation is more sensitive to the 2 plant growth regulators than the plant itself.

Jana \& Choudhuri (1983) found that plant senescence was delayed by cytokinin. In the present study, the plant growth period in Potamogeton crispus was found to be prolonged by $\mathrm{GA}_{3}$ and 6-BA, due to the inhibition of propagule formation. This may contribute to the use of the plant to improve water quality because of a longer growing period. However, as propagule production can be substantially inhibited when the plant is exposed to these substances either for a short term at high concentrations or repeatedly at low concentrations during turion morphogenesis, this could be detrimental to the plant's regeneration and propagation over the course of years. In this regard, the runoff of cytokinins and gibberellins from farming or horticultural systems into bodies of water harbouring $P$. crispus should be controlled.

\section{Effects of physiological characteristics on propagule formation}

Plants rely on a wide variety of metabolic and physiological responses to adapt their growth and development to variations in the environment. When a storage organ is forming, metabolism in source stems and leaves may decrease and assimilation availability transferred to sink tissue (McCormick et al. 2006), which consequently affects plant growth. Spencer et al. (1994) noted that once Hydrilla verticillata is initiated to produce propagules under short photoperiods $\left(11 \mathrm{~h} \mathrm{~d}^{-1}\right)$, nitrogen and carbon are directed from shoots and roots into newly formed tubers and turions. Spencer \& Anderson (1987) also found decreases in chl $a$ and carotenoids in leaves coinciding with propagule formation in Potamogeton nodosus. In the present study, the contents of photosynthetic pigments increased in plants in both $\mathrm{GA}_{3}$ and 6-BA treatments except for in BALS compared to the control. This implies that the inhibition of propagule production by gibberellin and cytokinin is also associated with increases in photosynthetic pigments in the plant.

The regulatory functions of hormones on the sink-source relationship have well been established in some terrestrial plants, although the roles of endogenous hormones in these processes remain unknown (Baker 2000). In the present study, we found that the accumulation of starch reserve in propagules declined significantly under all applications of $\mathrm{GA}_{3}$ and 6-BA in Potamogeton crispus. Starch content decreased to different degrees, but soluble sugar, sucrose, and reducing sugar contents increased in the propagules, demonstrating that the starch synthesis from sugars was retarded. Furthermore, the changes in the carbohydrate content in propagules were dosesensitive under $\mathrm{GA}_{3}$ single-application: the contents of soluble sugar, sucrose, and reducing sugars increased and starch content decreased with increasing $\mathrm{GA}_{3}$ concentration. But under 6-BA single-application, the contents of all carbohydrates were lower at high concentration than at low concentration, implying that 
the inhibition of starch synthesis in propagules might be partially attributed to lower influx of assimilates into the propagules in the high-concentration 6-BA treatment, in comparison with low concentration. However, analysis showed that there were no corresponding changes in carbohydrate contents of plants in contrast to the propagules under the 2 regulator treatments. The regulation of gibberellin and cytokinin on the sink-source relationship in propagule formation of $P$. crispus remains largely unknown and needs further investigation.

\section{CONCLUSIONS}

The results of the present study are conducive towards explaining the regulation on propagule formation by plant hormones, which may be involved in the population decline of some submerged aquatic plants such as Potamogeton crispus in eutrophic waters. Propagule production was inhibited or delayed by applying $\mathrm{GA}_{3}$ or 6-BA to $P$. crispus. The effect became greater with increasing concentrations and number of applications. 6-BA inhibited the differentiation of the propagule, but had little effect on its growth. $\mathrm{GA}_{3}$ not only inhibited propagule formation, but also induced some standard turions to develop into phylloclade turions. The effects of the 2 regulators on propagule formation were coincident with promoting photosynthetic pigments in the plants and inhibiting starch accumulation in the propagules. Both plant growth regulators had stronger effects on propagule formation than on plant growth. In this regard, reduced discharge of cytokinin- and gibberellin-type regulators from farming or horticultural systems into waterways should be enforced to protect natural regeneration and propagation of $P$. crispus.

Acknowledgements. This work was part of the Research and Demonstration on Agro-Ecological Restoration Technology in Danjiangkou Reservoir Region for the South-to-North Water Transfer Project (grant no. 2007BAD87B09). We thank the National Natural Science Foundation of China (40973056) and the Natural Science Foundation of Hubei Province (2005ABA042) for financial support, Assoc. Prof. Anguo Liu for meteorological data; Assoc. Prof. Bo Qu for statistical analysis, and Assoc. Prof. Guosheng Xie for comments on the language and grammar of the manuscript.

\section{LITERATURE CITED}

Ali MB, Tripathi RD, Rai UN, Pal A, Singh SP (1999) Physicochemical characteristics and pollution level of Lake Nainital (U.P., India): role of macrophytes and phytoplankton in biomonitoring and phytoremediation of toxic metal ions. Chemosphere 39:2171-2182

Baker DA (2000) Vascular transport of auxins and cytokinins in Ricinus. Plant Growth Regul 32:157-160

> Catling PM, Dobson I (1985) The biology of Canadian weeds. 69. Potamogeton crispus L. Can J Plant Sci 65: 655-668

> Chambers PA, Spence DHN, Eeeks DC (1985) Photocontrol of turion formation by Potamogeton crispus L. in the laboratory and natural water. New Phytol 99:183-194

> Chen XF, Chen KN, Xiao YE, Zhang SD, Wang QY (2006) Effects of light and matrix on turion germination, seedling growth and leaf photosynthesis efficiency of Potamogeton crispus. Chin J Appl Ecol 17:1413-1418 (in Chinese)

> Chow-Fraser P (1998) A conceptual ecological model to aid restoration of Cootes Paradise Marsh, a degraded coastal wetland of Lake Ontario, Canada. Wetlands Ecol Manag 6:43-57

> Dreywood R (1946) Qualitative test for carbohydrate material. Ind Eng Chem Anal Ed 18:499

Franco-Zorrilla JM, Martín AC, Leyva A, Paz-Ares J (2005) Interaction between phosphate-starvation, sugar, and cytokinin signaling in Arabidopsis and the roles of cytokinin receptors CRE1/AHK4 and AHK3. Plant Physiol 138:847-857

Friedrich J, Christian D, Erwin G, Silviu R, Dan S, Sandra S, Bernhard W (2003) Nutrient uptake and benthic regeneration in Danube Delta Lakes. Biogeochemistry 64: 373-398

Genkov T, Ivanova I (1995) Effect of cytokinin-active phenylurea derivatives on shoot multiplication, peroxidase and superoxide dismutase acitivities of in vitro cultured carnation. Bulg J Plant Physiol 21:73-83

Grace JB (1985) Juvenile vs. adult competitive abilities in plants: size dependence in cattails (Typha). Ecology 66: 1630-1638

Hansson LA, Helene A, Eva B, Stellan FH and others (1998) Biomanipulation as an application of food-chain theory: constraints, synthesis, and recommendations for temperate lakes. Ecosystems 1:558-574

Hu C, Zhang L, Hamilton D, Zhou W, Yang T, Zhu D (2007) Physiological responses induced by copper bioaccumulation in Eichhornia crassipes (Mart.). Hydrobiologia 579: 211-218

> Huang W, Chen KN, Bai X (2010) Effects of substrate nitrogen and phosphorus contents on Potamogeton crispus growth and reproduction. Chin J Appl Ecol 21:2865-2870 (in Chinese)

Hupfer M, Dollan A (2003) Immobilisation of phosphorous by iron-coated roots of submerged macrophytes. Hydrobiologia 506-509:635-640

James WF (2007) Growth response of Potamogeton crispus to lime application in experimental mesocosms. APCRP Technical Notes Collection. ERDC/TN APCRPEA-18. US Army Engineer Research and Development Center, Vicksburg, MS

> Jana S, Choudhuri MA (1983) ${ }^{32} \mathrm{P}$ uptake in three submerged aquatic plant species. Hydrobiol Bull 17:97-101

Klaine SJ (1986) Influence of thidiazuron on propagule formation in Hydrilla verticillata. J Aquat Plant Manag 24:80-82

Klaine SJ, Ward CH (1984) Environmental and chemical control of vegetative dormant bud production in Hydrilla verticillata. Ann Bot 53:503-514

> Kunii H (1989) Continuous growth and clump maintenance 
of Potamogeton crispus L. in Narutoh River, Japan. Aquat Bot 33:13-26

Lowry OH, Rosebrough NJ, Farr AL, Randall RJ (1951) Protein measurement with the Folin phenol reagent. J Biol Chem 193:265-275

McCormick AJ, Cramer MD, Watt DA (2006) Sink strength regulates photosynthesis in sugarcane. New Phytol 171:759-770

Mok MC, Mok DWS, Armstrong DJ, Shudo K, Isogai Y, Okamoto $\mathrm{T}$ (1982) Cytokinin activity of N-phenyl-N'1,2,3-thiadiazol-5-ylurea (thidiazuron). Phytochemistry 21:1509-1511

Ohkama-Ohtsu N, Wasaki J (2010) Recent progress in plant nutrition research: cross-talk between nutrients, plant physiology and soil microorganisms. Plant Cell Physiol 51:1255-1264

Rogers KH, Breen CM (1980) Growth and reproduction of Potamogeton crispus in a South African lake. J Ecol 68: 561-571

Sakakibara H, Takei K, Hirose N (2006) Interactions between nitrogen and cytokinin in the regulation of metabolism and development. Trends Plant Sci 11: $440-448$

Sastroutomo SS (1980) Environmental control of turion formation in curly pondweed (Potamogeton crispus). Physiol Plant 49:261-264

Sastroutomo SS (1981) Turion formation, dormancy and germination of curly pondweed, Potamogeton crispus L. Aquat Bot 10:161-173

Sastroutomo SS, Ikusima I, Numata M, Iizumi S (1979) The importance of turions in the propagation of pondweed (Potamogeton crispus L.). Annu Rev Ecol Syst 19:75-88

Sculthorpe CD (1967) The biology of vascular aquatic plants. St. Martins Press, New York, NY

Shen J, Xu W, Shi FC (2008) Effects of weight and store temperature on turion germination and seedling growth of Potamogeton crispus L. Bull Bot Res 28:477-480 (in Chinese)

Smart CC, Trewavas AJ (1983) Abscisic-acid-induced turion formation in Spirodela polyrrhiza L. I. Production and development of the turion. Plant Cell Environ 6:507-514

Editorial responsibility: Hans Heinrich Janssen, Oldendorf/Luhe, Germany
Spencer DF, Anderson LWJ (1987) Influence of photoperiod on growth, pigment composition and vegetative propagule formation for Potamogeton nodosus Poir. and Potamogeton pectinatus L. Aquat Bot 28:103-112

> Spencer DF, Rejmanek M (1989) Propagule type influences competition between two submersed macrophytes. Oecologia 81:132-137

Spencer DF, Anderson LWJ, Ksander G, Klaine S, Bailey F (1994) Vegetative propagule production and allocation of carbon and nitrogen by monoecious Hydrilla verticillata (L.f.) Royle grown at two photoperiods. Aquat Bot 48: 121-132

Takei K, Sakakibara H, Taniguchi M, Sugiyama T (2001) Nitrogen-dependant accumulation of cytokinins in root and the translocation to leaf: implication of cytokinin species that induces gene expression of maize response regulator. Plant Cell Physiol 42:85-93

> Tobiessen P, Snow PD (1984) Temperature and light effects on the growth of Potamogeton crispus in Collins Lake, New York State. Can J Bot 62:2822-2826

Van TK, Haller WT, Garrard LA (1978) The effect of daylength and temperature on Hydrilla growth and tuber production. J Aquat Plant Manag 16:57-59

Weber JA, Nooden LD (1976) Environmental and hormonal control of turion formation in Myriophyllum verticillatum. Plant Cell Physiol 17:721-731

Werner T, Schmülling T (2009) Cytokinin action in plant development. Curr Opin Plant Biol 12:527-538

Woolf TE, Madsen JD (2003) Seasonal biomass and carbohydrate allocation patterns in southern Minnesota curlyleaf pondweed populations. J Aquat Plant Manag 41:113-118

- Wu J, Cheng S, Liang W, He F, Wu Z (2009) Effects of sediment anoxia and light on turion germination and early growth of Potamogeton crispus. Hydrobiologia 628: 111-119

Yang X, Zhang X, Yu S, Wang J (2010) Analysis on efficiency of constructed wetland in treatment micro-polluted water resource and effect of plants. Chin Agric Sci Bull 26:274-278 (in Chinese)

> Yemm EW, Willis AJ (1954) The estimation of carbohydrates in plant extracts by anthrone. Biochem J 57:508-514

Submitted: December 8, 2010; Accepted: December 15, 2011 Proofs received from author(s): March 3, 2012 